\title{
Effects of Meditation on one's emotional life : a pre-post case series study
}

\author{
Simmin Bawa ${ }^{1}$ \\ ${ }^{1}$ Asst. Professor and Head, Department of Philosophy, Jaihind College, Mumbai \& Practicing \\ Holistic Healer, Mumbai. \\ E-mail-simminbawa@gmail.com
}

\begin{abstract}
This study aims to emphasize the effects of mediation in our emotional lives. Meditation is often viewed from a mystical lens especially for those who are considered God-intoxicated or those aiming for spiritual self-realization (with or without belief in God). It's a belief that meditation is a religious process whereas meditation is a non-denominational process meant for theist, atheist and agnostics. Apart from the spiritual, mediation has a broader salutary role to play in both physiological as well as psychological wellbeing of an individual. There is a close relation between the physiological and psychological wellbeing of an individual hence many ailments are considered to be psychosomatic. The paper aims to highlight the effects of mediation on individual's emotional lives.
\end{abstract}

Key words: meditation, emotional health, physical health, case study.

\section{INTRODUCTION}

Meditation is used as an effective tool to deal with issues arising in our emotional health. Meditation is understood as a practice in which an individual trains the mind to focus on only one focal point or object (a religious symbol like Om, etc. or image of a deity or guru or just awareness of a specific place on the body like space between two eye brows or nose, etc.) while consciously discarding all other thoughts. At a higher level, the mind is blanked out completely; a feeling of nothingness or zeroness. No thought or any modification of thoughts should take place. In such states, one loses awareness of the existence of the external world and even one's own body. Meditative practices are of various kinds. Many meditative cultural traditions exist and are generally identified with the guru (teacher) or school of thought and sometimes by the distinctive methodical text. Hence a precise definition of meditation becomes unfeasible. A general understanding of the term is a state in which the practitioner moves beyond the cognitive state of mind to a more silent, calm, tranquil and unperturbed state free from all mental mutations [1].

When we talk of human health, we consider only physical wellbeing though mental and emotional states play a vital role in our health as well. The terms mental and emotional health are used synonymously but the two differ. Keeping our attention focused on certain tasks requires our brain to process information, storing 
it in memory and above all comprehending and understanding it are aspects of mental health. In simple terms, mental health involves cognitive thinking, deductive reasoning and processing new information. Additionally, it involves volitional reasoning, forming opinions, making conscious reasonable choices and using logic in the process of decision making. Emotional health involves being able to express emotions in an appropriate manner. Since emotional health range and control varies by age and other factors, it is difficult to determine it. Optimal emotional health is typically defined as presence of positive management and expression of emotions while not showing reactions of unhealthy stress or depression. Though mental and emotional health are different concepts, one cannot exist without the other. Our day to day choices is dependent upon cognitive choices which may be influenced by our feeling or emotional responses towards it and vice-versa. Individuals who cannot balance the two develop problems like depression, high levels of stress, anxiety, etc [2]. Responses of every individual to stressful events vary but the key is to learn to balance between the two and meditation can help in this endeavour as it silences and gives direction to the wild mind which in turn helps control emotions and make rational choices.

Meditation is a practice in which an individual trains the mind or induces a mode of consciousness. Patanjali yoga states in the deepest state of meditation, we reach a state of chitta vritti nirodha which means cessation of all mental modifications and this should be our aim in life [3]. Others state that meditation is also pragmatically benefitted to either realize some benefit or as an end in itself. Researchers asserts that in every meditation system, the single invariant ingredient is the need for the meditator to retrain his attention, whether through concentration or mindfulness. Meditation is often used to strike a balance in the human being; a balance of the physical, mental, emotional, intellectual and spiritual well-being [4]. For some, meditation refers to a family of self-regulation practices which to bring mental processes under voluntary greater control, focus on training attention and awareness. This fosters general mental well-being. It also develops general and specific capacities such as calmness, clarity and concentration. People who meditate find a change in their overall well-being. It helps to cure physical ailments as well. Those suffering from anger management issues, anxiety, restlessness and even blood pressure are asked to meditate to calm down. Meditation gives an individual a better insight into bothersome issues which creates stress in our lives. Meditation is recommended to people who are unable to bare the loss of a loved one or a romantic break-up or even work-related stress. Some find it beneficial while some don't. Also the attitude towards it matters [5]. Some authors say that regulation of attention is the central commonality across the many divergent methods. For them, meditation affects mental events by engaging a specific attention set which is because meditation is used to describe practices that self-regulate the body and mind [6].

\section{METHODOLOGY}

The aim of this study was to observe the effects of meditation on emotional life of practitioners. A self-constructed socio-demographic scale was developed. A total sample of 27 homogeneous people were chosen - 16 males and 11 females in the age group of 14-42. Participants were taught different techniques of meditation, depending upon their temperament and health (physical and emotional). Most had knowledge of at least one such technique and some were trained in up to five such practices. Each meditated for a minimum of 30 minutes and maximum 80 minutes per day either in 
groups or on their own and some even under the guidance of a trained teacher for a duration of six months.

All the chosen people suffered from:

a) emotional issues like depression, work-related and relationship-related stress.

b) poor physical health like insomnia, polycystic ovary syndrome, sever hair and weight loss and breast cancer.

For the purpose of study, four unique participants were selected for case studies.

\section{Tools Used}

a) Case studies to assess socio-demographic variables and familial and interpersonal factors before and after meditation.

b) Open ended interview schedule and self-constructed questionnaire comprising of questions using concepts of emotional health, meditation, healthy practices of people, level of physical and mental health they experience were included.

\section{CASE SERIES}

\section{Case A}

This case study is a 14 year old boy, only son belonging to a family of well-known doctors. He was constantly pressurized by parents, extended family, friends and acquaintances to excel academically and carry the family legacy. The boy could not handle the pressure appropriately and suffered from insomnia, palpitations and feared failure. His scores started plummeting. Fear of failure started manifesting in his dreams and he experienced failure related night mares. He confided the above in two trusted teachers who in turn spoke to his parents and recommended they approach a counsellor. The counsellor suggested regular counselling and practice of meditation to calm down. The boy's parents chose to make him learn the Jaina technique of meditation, Preksha Dhyana as they were practising Jains. To supplement this, he also enrolled for yoga classes where he was taught physical (asanas) and breathing exercises (pranayama) along with meditation to calm down.

\section{Case B}

The following case study is of a 27 year old lady who was academically brilliant; pursuing second year MBA in Finance (part time) and working for a reputed advertising agency. In three months she was due for promotion when her fiancé - a practising chartered accountant - decided to call off their wedding. Reason given by her fiancé was that she was too ambitious and focused on her career as a result of which she was unable to give enough quality time to the relationship. He felt she took the relationship for granted and that the relationship could not sustain in the long run without making sacrifices. All along she felt her fiancé was supportive of her career and understanding the demands of her job. She was chronically depressed and became withdrawn. Besides losing interest in work and academics, she lost nine kilograms of weight in three weeks due to loss of appetite, suffered severe thyroid hormone imbalance and hair loss. Medical practitioners and her counsellor suggested along with medication, she should learn some form of meditation and practice regularly. Her friends recommended that she learns the Buddhist technique of meditation, Vipassana; as they were themselves practioners and great beneficiaries. She decided to go by the choice made by her friends as she had never meditated before. 


\section{Case C}

This case study is of a 42 year old man working for a company where he was heading the marketing department. After working in the company loyally with full dedication for seven years, he was one day served a termination letter. Reasons cited by the company were that they were suffering loses and to cut costs had resorted to down-sizing and contract based employment. Being demoralized and losing confidence in his abilities, he wasn't able to convince himself to appear for job interviews. He was chronically depressed. His supportive family took him for psychiatric treatment. His wife's close friend was a holistic healer who suggested meditation with a few semiprecious crystals along with chanting of the mystic syllable 'AUM'. Even though he was an atheist, he did not resist and gave his approval to start meditating and chanting.

\section{Case D}

The following case study is of a 45 year old housewife; victim of domestic violence. Her husband was an alcoholic wife-beater and mother-in-law was authoritarian, always demanding dowry. The lady was allowed to work but her unemployed husband would spend all her money on alcohol. She had to somehow provide for her two sons on her own. Husband died due to liver malfunction. Hearing this news, the lady's mother-in-law fell very ill and expired after few months. The lady had the support of her two loving sons. After a year of release from domestic violence, she developed a lump in her left breast and was diagnosed with breast cancer. After listening to the lady's health status, her spiritual guru intuitively felt that cancer had developed due to suppressed emotional issues and past abuse. He recommended that she meets a counsellor to confide in and vent her emotional issues and also practise meditation which would help nurse emotional wounds. The spiritual guru collected donations to fund her medical treatment and counselling sessions. She began meditating on the guidance provided by her spiritual guru. He never followed any fixed style of meditation and kept changing it on a regular basis.

\section{Analysis of the Cases}

\section{State of emotional and physical health prior to meditation}

Except for the cancer patient, all participants were emotionally weak and sensitive to any comments made by near and dear ones. They were unable to make and take decisions and their self-esteem was low. The cancer patient had no hope to recover and fight back the dreadful disease and often expressed desire to die. Size of her cancerous tumour increased and was spreading at a slow pace. The 14 year old boy didn't want to study and appeared lost all the time. He had become a social recluse. Insomnia set in for him which adversely affected his classroom performance. The 27 year old lady, didn't feel like doing anything and often took leave from work besides giving up on her MBA course. She used to cry for hours without reason; withdrew in a shell and preferred her own company. Her weight and hair loss increased; menstrual irregularities set in and she developed polycystic ovary syndrome. The family of the 42 year old man would send his bio-data to various companies and if call letters for interviews would come, the man would resist and not go for any interview.

\section{State of emotional health after meditation}

The participants meditated regularly and after three months, three participants showed drastic improvement. The school boy had accepted that he was taking undue pressure and decided to develop a few hobbies to deal with the stress. He 
took to listening music of various genre's and go for swimming two or three times a week besides taking keen interest in studies. He continued meditating and developed faith in himself to excel. He discontinued yoga as he disliked its slow pace. The 27 year old lady decided to accept the failure of her relationship but decided to move on, focus on work which she liked the most; feeling happy after making peace with herself. She made time from her busy schedule to meditate regularly and this helped her in focusing at work. The cancer patient was adamant to fight out her cancer and to do something for other women who were victims of domestic violence. She enjoyed meditating and also took keen interest in spirituality. Even though the 42 year old man meditated regularly, only his emotional state showed no improvement. He still did not come to terms with his past and the circumstances under which he lost his job.

\section{Improvement in Physical/Emotional Ailments after meditating}

Three out of four participants showed improvement in physical and emotional health. The school going boy had learnt to deal with pressures and learnt to accept comments made by others about him carrying on the family tradition of medical practitioners. He began enjoying studies and did not think much about the future. His new found hobbies of swimming and listening to music helped him further. He started socializing at the health club where he would go swimming and joined a few online music appreciation clubs. Only when he felt the need to talk, did he visit the counsellor. The 27 year old lady, immersed herself in work, got her promotion and was even sent abroad for some training by her company. Her weight and hair loss improved and with hormonal treatment her polycystic ovaries syndrome showed positive signs of improvement. She stopped going to the counsellor but continued regular meditation. Her self-esteem improved and her concentration at work too. Even though she socialized less, she reported not having the urge to do so. The cancer patients' tumour shrunk to a size where oncologists could operate and remove it. The operation was successful but she had to continue with chemotherapy and radiation. She continued meditating during her entire treatment period and reported to being determined to fight the illness. Only the 39 year old man showed no improvement. He just could not move on in life and continued dwelling on the loss of his job. After sometime, even his family had lost hope that he will ever recover. It seemed to them that he did not want to come out of the past. His medication and meditation were going on simultaneously. Yet there was no improvement on the emotional front.

\section{Improvement in Interpersonal Relationships at school/work and home}

The school going boy and the 27 year old lady showed some improvement in their interpersonal relationships. They were able to communicate better to their families about their situation. The school going boy even spoke to his parents that they should be ready to accept that he may not take up the medical field; whereas the lady told her parents not to pressurize her to get married and settle down. She still believed in love and felt that she would find her ideal soulmate someday. The boy performed better at school and his improvement was even noted by his teachers. The cancer patient showed remarkable improvement in her physical ailment and even came out of her shell, from an under confident and an introvert personality became more social and started talking and helping women suffering from breast cancer and domestic violence, whereas the 42 year old man showed no improvement in his interpersonal relationships. 


\section{Relationships}

School going boy made a group of friends at the health club and would regularly socialize with them. Most were elder to him and he enjoyed their company. He even spoke about developing transparent, open and cordial relations with his parents. The cancer patient bonded well with her children and other women who were victims of domestic violence and suffering from breast cancer. She communicated and bonded very well with them. As she had taken up to singing devotional spiritual songs (bhajan), she used it to calm these women, giving them hope to fight for a better tomorrow. The 27 year old lady, spoke honestly and assertively with her parents. She reported to having socialized with her extended family more frequently but not form friendly relations otherwise. The 39 year old man felt closer to his immediate family though overall there was no improvement in his emotional life.

\section{Work life}

The 27 year old lady, reported that meditation helped her calm down in tense situations and felt more creative than before; more in control of her life. The cancer patient too reported feeling creative to deal with women suffering with breast cancer and creating devotional songs. Her attitude of servitude increased and she felt humble and strong overall.

\section{Scope for further research}

The study should continue for a longer period of time. Some victims of breast cancer patients suffer from a relapse and it spreads to the other breast. Continued counselling, changing the course of meditation, medication and maybe change in environment might help the 39 year old man. One must follow the case of the 27 year old lady to see if she dates someone again which culminates it into a marriage. She might have to make adjustments and sacrifices; make time for her family life. Also, would the school going boy excel academically and voluntarily studies medicine.

\section{Limitations of the present approach}

- Number of case studies should have been larger to draw some generalized conclusions from the project.

- Study was carried out only in Mumbai city.

- Gender wasn't considered as a variable.

- More than one form of meditation was used depending on individual requirements.

- Only participants self-report was taken for assessing their state of mental and physical health.

\section{Conclusions}

Meditation positively helps those who wish to improve their healthphysical and emotional. Improvement in the state of the emotional and physical health was observed for three participants. Further meditation also enhanced their interpersonal skills and social life. The 39 year old man seemed to be drowned in selfpity and was not strongly willing to come out of his condition. But meditation alone will not do. When physical ailments arise, medical intervention is essential along with proper dietary regulations. Also, when emotional issues arise, if too severe and chronic, meditation should complement with professional counselling and sometimes psychiatric 
treatment as well. On the whole, meditation can be performed with or without these health related incentives. It is both, a means to an end; as well as an end in itself.

\section{REFERENCES}

1. Baba B. Yogasutra Patanjali - With the Commentary of Vyasa. Delhi, India: Motilal Banarsidass Publishers Pvt. Ltd ; 2002.

2. Patel G. Stress Free Living in $21^{\text {st }}$ Century. Mumbai, India ; 2010.

3. Patel G. Science of Spirituality. Mumbai, India ; 2009.

4. Sandhu M. Meditation : an outline for practical study. UK: Karnac Books ; 2007.

5. Kornfield J. Meditation for Beginners. Jaico Publishing House: Delhi ; 2010.

6. Yogani S. Deep Meditation : the pathway to personal freedom. AYP Publications ; 2005.

Acknowledgements - Nil

Conflict of Interest - Nil

Funding - Nil. 